\title{
A case report
}

\section{Vicenta Pujol-Blaya', Ma LI Torrent' ${ }^{2}$,Antonieta Falco'}

'Lymphedema Unit. ${ }^{2}$ Burns Unit. 1,2Physical Medicine and Rehabilitation Department. Hospital Universitari Vall d'Hebron , Barcelona, Spain

\section{INTRODUCTION}

The incidence of lymphedema secondary to burns is uncertain; there are no epidemiological studies in the scientific literature

\section{CASE REPORT}

We present the case of a burned patient with an affectation of the $80 \%$ of the body surface with second and third-degree burns of years of evolution.

The patient has required multiple corrective surgical procedures, presenting important retractions and amputation of upper extremities phalanges.

In spite of everything, the patient partially maintains her autonomy thanks to the functional clamp of both hands. In the postoperative course of an excision of a periarticular calcification of the elbow, presents clinical edema of the hand dorsum and first right phalanx with the loss of manual ability.

On examination, a pitting edema without stemmer sign is detected due to the absence of skin folds.

The predisposing factors for lymphedema were the circumferential involvement and depth of the burn, scar retraction and the trauma derived from the intervention.

In our case, the challenge was to find a customized decongestive system with which maintain her autonomy, thus we opted for a selfadjusting low elasticity device with lymphatic padding.

\section{CONCLUSION}

Self-adjusting systems allow us to regulate working pressure during the day while molding to different surfaces.

They have the additional advantage that they allow self-management with respect to the pathology reducing health costs derived from therapy

\section{Bibliography}

I- Hettrick HI, Nof L, Ward S, Ecthernach J. Incidence and prevalence of lymphedema in patients following burn injury: a five-year retrospective and three-month prospective study. Lymphat Res Biol. 2004;2(I): I -24

2 - Chenicheri Balakrishnan, MD, Lisa M Bradt, RN, Abdullah J Khalil, MD, and John M Trupiano, MD. Lymphedema of the upper extremity following circumferential burns. Can J Plast Surg. 2004 Summer; I2(2): 79-80
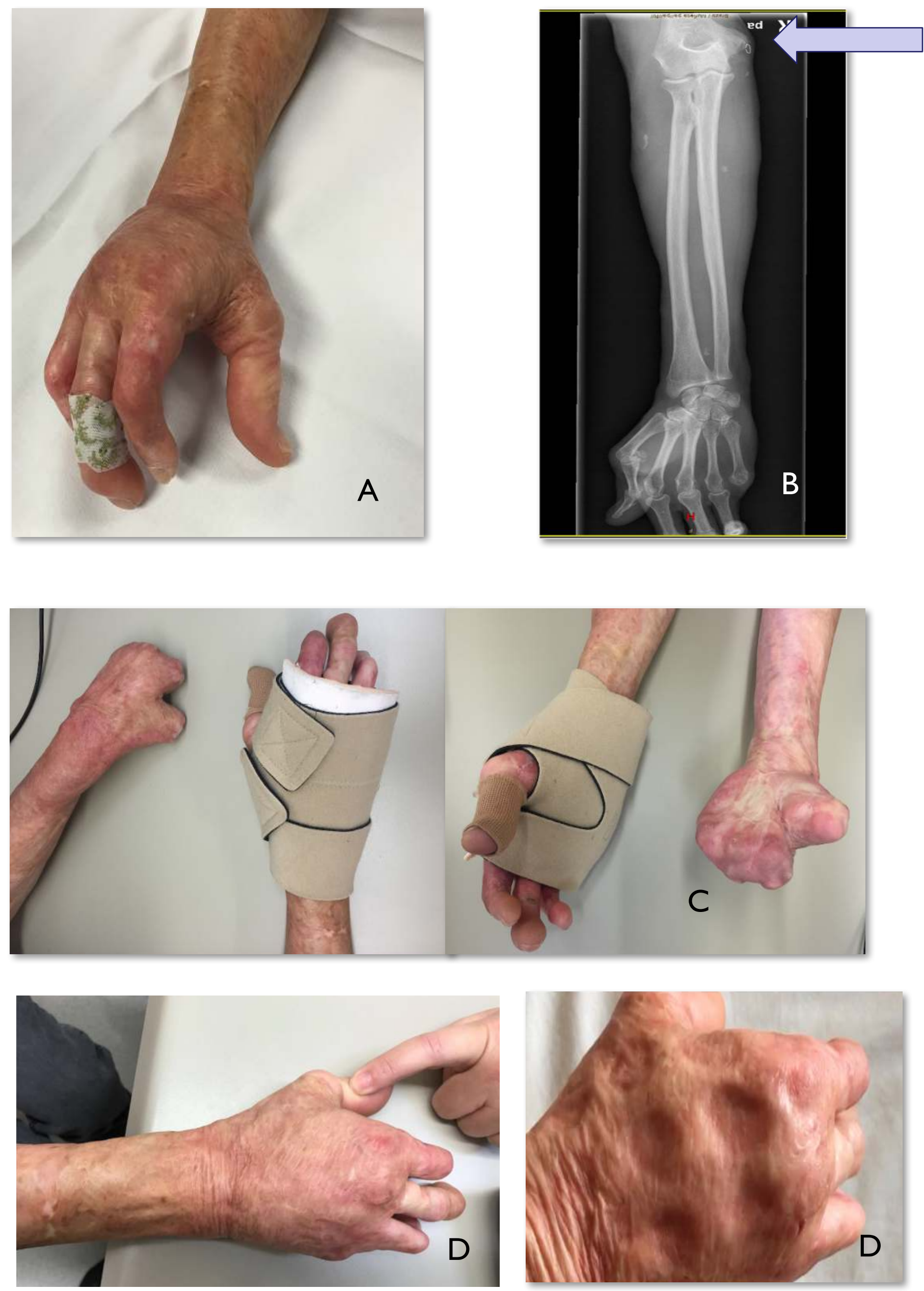

A. Lymphedema at the dorsum of the hand. B. Periarticular calcification of the elbow. C. Adjustable inelastic wrap with lymphatic pad. D. Before and after the use of the device, we appreciate the removal of lymph
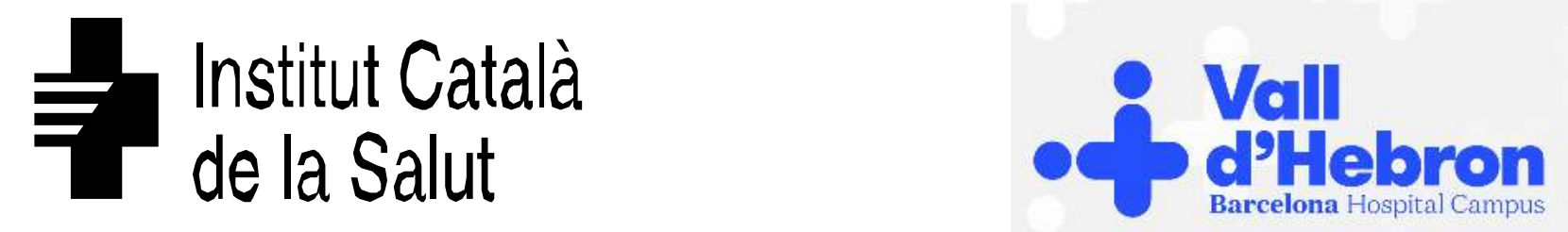